Article

\title{
Human Cytomegalovirus Is Associated with Lower HCC Recurrence in Liver Transplant Patients
}

\author{
Po-Jung Hsu ${ }^{1}$, Hao-Chien Hung ${ }^{2}{ }^{\circledR}$, Jin-Chiao Lee ${ }^{2}{ }^{\oplus}$, Yu-Chao Wang ${ }^{2}$, Chih-Hsien Cheng ${ }^{2}$, Tsung-Han $\mathrm{Wu}^{2}$, \\ Ting-Jung $\mathrm{Wu}^{2}{ }^{2}$, Hong-Shiue Chou ${ }^{2}$, Kun-Ming Chan ${ }^{2}$, Wei-Chen Lee ${ }^{2}$ and Chen-Fang Lee ${ }^{2,3, *}$ \\ 1 Department of General Surgery, Chang-Gung Memorial Hospital, Linkou 333, Taiwan; mr1661@cgmh.org.tw \\ 2 Department of Liver and Transplantation Surgery, Chang-Gung Memorial Hospital, Linkou 333, Taiwan; \\ mp0616@cgmh.org.tw (H.-C.H.); b9302012@cgmh.org.tw (J.-C.L.); b9002072@cgmh.org.tw (Y.-C.W.); \\ chengcchj@cgmh.org.tw (C.-H.C.); domani@cgmh.org.tw (T.-H.W.); wutj5056@cgmh.org.tw (T.-J.W.); \\ chouhs@cgmh.org.tw (H.-S.C.); chankunming@cgmh.org.tw (K.-M.C.); weichen@cgmh.org.tw (W.-C.L.) \\ 3 College of Medicine, Chang-Gung University, Taoyuan 333, Taiwan \\ * Correspondence: lee5310@cgmh.org.tw; Tel.: +886-3-3281200 (ext. 3366); Fax: +886-3-3285818
}

check for updates

Citation: Hsu, P.-J.; Hung, H.-C.; Lee, J.-C.; Wang, Y.-C.; Cheng, C.-H.; Wu, T.-H.; Wu, T.-J.; Chou, H.-S.; Chan, K.-M.; Lee, W.-C.; et al. Human Cytomegalovirus Is Associated with Lower HCC Recurrence in Liver Transplant Patients. Curr. Oncol. 2021, 28, 4281-4290. https://doi.org/ 10.3390 /curroncol28060364

Received: 19 September 2021 Accepted: 19 October 2021 Published: 21 October 2021

Publisher's Note: MDPI stays neutral with regard to jurisdictional claims in published maps and institutional affiliations.

Copyright: (c) 2021 by the authors. Licensee MDPI, Basel, Switzerland. This article is an open access article distributed under the terms and conditions of the Creative Commons Attribution (CC BY) license (https:/ / creativecommons.org/licenses/by/ $4.0 /)$.

\begin{abstract}
Human cytomegalovirus (CMV) infection has been reported to compromise liver transplantation (LT) outcomes. Recent studies have shown that CMV has a beneficial oncolytic ability. The aim of this study was to investigate the impact of CMV on tumor recurrence in patients with hepatocellular carcinoma (HCC) who underwent liver transplantation (LT). This retrospective study enrolled 280 HCC patients with LT at our institute between January 2005 and January 2016. Their relevant demographic characteristics, pre- and post-LT conditions, and explant histology were collected. A CMV pp65 antigenemia assay was performed weekly following LT to identify CMV infection. A total of 121 patients (43.2\%) were CMV antigenemia-positive and 159 patients (56.8\%) were negative. A significantly superior five-year recurrence-free survival was observed among CMV antigenemia-positive patients compared with the CMV-negative group (89.2\% vs. $79.9 \%, p=0.049)$. There was no significant difference in overall survival between the positive and negative CMV antigenemia groups $(70.2 \%$ vs. $75.3 \%, p=0.255)$. The major cause of death was HCC recurrence in CMV antigenemia-negative patients (51.3\%), whereas more CMV antigenemia-positive patients died due to other bacterial or fungal infections (58.3\%). In the multivariate analysis, the independent risk factors for tumor recurrence included positive CMV antigenemia $(p=0.042$; odds ratio $(\mathrm{OR})=0.44$; $95 \%$ confidence interval $(\mathrm{CI})=0.20-0.97)$, microscopic vascular invasion $(p=0.001 ; \mathrm{OR}=3.86 ; 95 \%$ confidence interval $(\mathrm{CI})=1.78-8.36)$, and tumor status beyond the Milan criteria $(p=0.001 ; \mathrm{OR}=3.69$; $95 \% \mathrm{CI}=1.77-7.71)$. In conclusion, in addition to the well-known Milan criteria, human CMV is associated with a lower HCC recurrence rate after LT. However, this tumor suppressive property does not lead to prolonged overall survival, especially in severely immunocompromised patients who are vulnerable to other infections.
\end{abstract}

Keywords: cytomegalovirus; hepatocellular carcinoma; liver transplantation

\section{Introduction}

Since the introduction of the Milan criteria (single tumor with diameter $\leq 5 \mathrm{~cm}$, up to three tumors with diameter $\leq 3 \mathrm{~cm}$, and no major vessel or extrahepatic involvement) [1], liver transplantation (LT) has served as one of the treatment choices for patients with an unresectable hepatocellular carcinoma (HCC). The five-year overall survival (OS) of patients with HCC who underwent LT exceeds 70\% [1] Nevertheless, the reported HCC recurrence rate is $8-20 \%$ following transplantation [2-5]. Once HCC recurs, the estimated five-year overall survival decreases to $22-43 \%[2,4]$. As a result, preventing HCC recurrence after LT remains an important issue, and many risk factors associated with tumor recurrence have been identified, such as tumor behavior, differentiation type, alpha-fetoprotein (AFP) level, and serum neutrophil-to-lymphocyte ratio [2,3]. 
Human cytomegalovirus (CMV), one of the most common opportunistic infections following transplantation, has been reported to increase the risk of allograft failure and compromise post-LT outcomes [6,7]. A high plasma CMV DNA load indicates a risk of developing major post-transplant complications [8]. Interestingly, recent studies have revealed that CMV has potential oncolytic activity, inducing apoptosis and stimulating immune cell infiltration in the tumor microenvironment [9]. Several human and animal models, based on various cancers, have demonstrated the anti-cancer ability of CMV in recent years [9-12]. Kumar et al. reported that CMV could limit tumor cell proliferation and enhance tumor cell apoptosis in a murine model [11].

Since clinical data showing this oncolytic effect are scarce, we are interested in investigating whether CMV can play a beneficial antitumor role after liver transplantation in the real world. The aim of this study was to clarify the impact of CMV on tumor recurrence and overall survival in HCC patients after LT. We have attempted to provide a novel viewpoint of viral infectious disease in this immunocompromised population.

\section{Materials and Methods}

\subsection{Patient Enrollment and Data Collection}

This was a retrospective study of consecutive LT cases with HCC at Chang Gung Memorial Hospital at Linkou from 2005 to 2016. We excluded patients who died early post-transplantation (within 90 days) or who had no sufficient follow-up period to monitor the primary outcome or tumor recurrence. Patients who were missed for follow-up or had incomplete data were also excluded. A total of 280 patients were enrolled in the study. Their relevant demographic characteristics, preoperative conditions, post-LT outcomes, explant histology, and CMV antigenemia data were collected. The protocol of this retrospective study was approved by the Ethics Committee and Institutional Review Board of Chang Gung Memorial Hospital (approval no. 202101491B0) and conformed to the ethical guidelines of the 1975 Declaration of Helsinki.

\subsection{Liver Transplant Protocol and HCC Patients Selection}

The pre-transplant evaluation, preparation, and procedures of liver transplantation were reported in our previously published studies [13-15]. Most of our patients received the right lobe from living donors they were related to. Milan criteria were used for the selection of HCC patients who were planning to receive LT. However, tumor status not beyond the University of California San Francisco (UCSF) criteria (solitary tumor $\leq 6.5 \mathrm{~cm}$ or up to three tumors $\leq 4.5 \mathrm{~cm}$ ) [16] was also allowed. In our institute, the primary immunosuppression protocol consists of administering tacrolimus, corticosteroids, and mycophenolate mofetil. The dosage and titration protocols are described elsewhere [15].

\subsection{Serological Study and Standardization of CMV Surveillance}

All recipients underwent serological tests for CMV antibodies (IgM and IgG) using an enzyme-linked immunosorbent assay before live transplantation. We routinely performed the CMV pp65 antigenemia assay weekly following liver transplantation until the patient was discharged or died. The present study did not include CMV quantitative polymerase chain reaction (qPCR) results because CMV qPCR has only been performed in our hospital since 2017.

\subsection{Definition of CMV pp65 Antigenemia and CMV Disease}

The protocol for the CMV pp65 antigenemia assay was documented in our previous study [8]. In brief, a blood sample was collected and an antigenemia assay was conducted within $6 \mathrm{~h}$ using the MonoFluoTM Kit CMV 52206 Immunofluorescence Assay (IFA; BioRad, Hercules, CA, USA). CMV pp65 was targeted by a monoclonal antibody in the kit and visualized with a fluorescent secondary antibody. Positive CMV pp65 antigenemia was defined as at least one CMV pp65 antigen targeted by a monoclonal antibody per $500 \times 10^{3}$ peripheral blood leukocytes. 
CMV disease was defined as the coexistence of documented positive CMV pp65 antigenemia and clinical symptoms, such as unexplained fever, thrombocytopenia $\left(<150 \times 10^{3} / \mu \mathrm{L}\right)$, leukopenia $(<4000 / \mu \mathrm{L})$, and/or atypical lymphocytosis ( $>5 \%)$ [17]. In the present study, we defined severe CMV disease as two or more organ systems involved when CMV disease occurred and eventually led to organ failure [18].

\subsection{Preemptive Treatment Protocol for $C M V$}

Based on their clinical conditions, patients started anti-CMV treatment with oral valganciclovir $900 \mathrm{mg}$ per day or intravenous ganciclovir $5 \mathrm{mg} / \mathrm{kg}$ twice per day once CMV antigenemia was detected, and treatment continued until the CMV pp65 antigenemia assay was negative.

\subsection{Post-Transplant Outcome Assessment}

Infection, acute cellular rejection, surgical complications, and tumor recurrence were the major post-LT events recorded in our study. The diagnosis of infection was based on positive culture results of blood, urine, ascites, or sputum specimens. We did not routinely perform liver allograft biopsy; acute rejection was defined as an elevation of $>30 \mathrm{IU} / \mathrm{L}$ of serum aspartate aminotransferase (AST) and alanine aminotransferase (ALT) within $24 \mathrm{~h}$, not due to other causes of hepatic transaminase elevation [19]. A major post-transplant complication was defined as Clavien-Dindo class IV or V, which meant that patients experienced life-threatening organ dysfunction or even death [20]. HCC recurrence was diagnosed when the tumor recurred in the liver graft or any place in the body after a period when the cancer could not be detected. For tumor surveillance after transplantation, serum AFP and Doppler ultrasound were performed every three months along with computed tomography (CT) every six months, or when suspicious liver nodules were detected by ultrasound or with rising serum AFP. Recurrence-free survival (RFS) and overall survival were the secondary outcomes of the study and were calculated from the day of transplantation to the date of tumor recurrence or death.

\subsection{Statistical Analysis}

Demographic characteristics were summarized as median values, mean values \pm standard deviations, or numbers with percentages. Categorical variables were compared between antigenemia-positive and antigenemia-negative patients using Pearson's chi-square test. Logistic regression analysis was used to predict the recurrence of HCC after liver transplantation. All potential variables identified in the univariate analysis $(p<0.010)$ were included in the multivariate model and utilized for backward selection. The five-year recurrence-free survival and five-year OS were compared using the Kaplan-Meier method. A two-tailed $p$-value of less than 0.05 was considered statistically significant. All statistical analyses were performed using SPSS statistics (version 22.0; SPSS Inc., Chicago, IL, USA).

\section{Results}

\subsection{Characteristics of the Entire Population}

The demographic data of 280 patients with HCC who underwent liver transplantation are summarized in Table 1 . Most recipients were male $(n=221,78.9 \%)$, and the median age in the overall cohort was 56 (mean value: $56 \pm 7.1$ ) years. The median value of the MELD (model for end-stage liver disease) score was 12 (mean value: $13.5 \pm 6.1$ ). The main etiologies of liver disease are hepatitis B (HBV) and hepatitis C (HCV) infection. Among all patients, $173(61.8 \%)$ had HBV and $79(28.2 \%)$ had HCV. Most of the patients underwent living donor liver transplantation $(n=233,83.2 \%)$ and received right lobe grafts ( $n=220,94.4 \%$ ) with a median graft-to-recipient-weight ratio (GRWR) of $0.92 \%$ (mean value: $0.98 \pm 0.22 \%)$. Before liver transplantation, $212(75.7 \%)$ HCC patients received bridging or downstaging locoregional treatment, including transarterial chemoembolization in 195 patients $(69.6 \%)$, radiofrequency ablation in 34 patients $(12.1 \%)$, and other treatments (percutaneous ethanol injection and radiotherapy) in 20 patients (7.1\%). 
Table 1. Demographic characteristics of 280 HCC patients underwent LT.

\begin{tabular}{|c|c|c|c|}
\hline Factors & $\begin{array}{l}\text { Median Value or Number } \\
\text { (Percentage) }\end{array}$ & Mean \pm SD & Range \\
\hline \multicolumn{4}{|c|}{ General characteristics } \\
\hline Recipient age & 56 & $56 \pm 7.1$ & $33-70$ \\
\hline Recipient gender, male & $221(78.9 \%)$ & & \\
\hline \multicolumn{4}{|c|}{ Pre-LT characteristics } \\
\hline MELD score & 12 & $13.5 \pm 6.1$ & $5-40$ \\
\hline Hepatitis B infection & $173(61.8 \%)$ & & \\
\hline Hepatitis C infection & $79(28.2 \%)$ & & \\
\hline LDLT & $233(83.2 \%)$ & & \\
\hline Right lobe in LDLT & $220(94.4 \%)$ & & \\
\hline GRWR $(\%)$ in LDLT & 0.92 & $0.98 \pm 0.22$ & $0.57-1.79$ \\
\hline Local regional treatment before LT & $212(75.7 \%)$ & & \\
\hline $\begin{array}{l}\text { Tumor status within Milan criteria (by } \\
\text { radiologic assessment) }\end{array}$ & $234(83.6 \%)$ & & \\
\hline AFP & 13.4 & $213.5 \pm 1168.2$ & $1-18,250$ \\
\hline \multicolumn{4}{|c|}{ Explant pathology characteristics } \\
\hline Recipient with solitary tumor & $109(38.9 \%)$ & & \\
\hline Maximum tumor size $(\mathrm{cm})$ & 2.4 & $2.8 \pm 1.6$ & $0-11$ \\
\hline Satellite nodules & $24(8.6 \%)$ & & \\
\hline Macroscopic vascular invasion & $17(6.1 \%)$ & & \\
\hline Microscopic vascular invasion & $52(18.6 \%)$ & & \\
\hline \multicolumn{4}{|c|}{ CMV study } \\
\hline Preoperative CMV IgG positive & $278(99.3 \%)$ & & \\
\hline PP65 antigenemia positive & $121(43.2 \%)$ & & \\
\hline PP65, maximum/per $500 \times 10^{3} \mathrm{PBL}$ & 2 & & $1-115$ \\
\hline Persistent antigenemia $>2$ weeks & $28 / 121(23.1 \%)$ & & \\
\hline Relapsed CMV antigenemia & $33 / 121(27.3 \%)$ & & \\
\hline Severe CMV disease & $6 / 121(5 \%)$ & & \\
\hline \multicolumn{4}{|c|}{ Clinical outcome } \\
\hline Follow-up period(months) & 82.5 & $84.3 \pm 49.4$ & 3-191 \\
\hline Five-year recurrence free survival, cumulative & $83.7 \%$ & & \\
\hline Five-year overall survival, cumulative & $73.1 \%$ & & \\
\hline Major complications & $23(8.2 \%)$ & & \\
\hline Cause of mortality in 5 years & & & \\
\hline Other bacterial or fungal Infection & $30 / 75(40.0 \%)$ & & \\
\hline HCC-related & $26 / 75(34.7 \%)$ & & \\
\hline Rejection & $8 / 75(10.7 \%)$ & & \\
\hline Others & $11 / 75(14.6 \%)$ & & \\
\hline
\end{tabular}

Abbreviation: HCC, hepatocellular carcinoma; LT, liver transplantation; SD, standard deviation; MELD, model of end-stage liver disease; LDLT, living donor liver transplantation; GRWR, graft recipient weight ratio; AFP, alpha-fetoprotein; CMV, cytomegalovirus; PBL, peripheral blood leukocytes.

Preoperative liver CT was routinely performed, and 234 patients (83.6\%) fulfilled the Milan criteria. The median value of pre-LT AFP was $13.4 \mathrm{ng} / \mathrm{mL}$. After reviewing all corresponding explant histology, 109 patients $(38.9 \%)$ had a solitary tumor, and the median maximum tumor size was $2.4 \mathrm{~cm}$ (mean value: $2.8 \pm 1.6 \mathrm{~cm}$ ). The presence of satellite nodules $(n=24,8.6 \%)$, macroscopic vascular invasion $(n=17,6.1 \%)$, and microscopic vascular invasion $(n=52,18.6 \%)$ were documented. Regarding the preoperative CMV serologic test, 278 patients (99.8\%) had positive CMV IgG results, and none of them had simultaneous positive CMV IgM. The CMV pp65 antigenemia assay was performed weekly after liver transplantation, and 121 patients (43.2\%) experienced one or more positive results in serial examinations. The maximum number of visualized pp65 counts per 500,000 in the weekly test among CMV antigenemia-positive patients was recorded, with a median value of 2 . Those cases with persistent antigenemia for more than two weeks and relapsed CMV antigenemia during the treatment course accounted for $23.1 \%(n=28)$ and $27.3 \%$ 
$(n=33)$, respectively. Despite the administration of anti-CMV regimens, six patients $(5 \%)$ developed severe CMV disease.

The median follow-up time was 82.5 months (mean: $84.3 \pm 49.4$ ). A total of 75 patients (26.8\%) expired within five years after LT, and the major causes of mortality were infection $(n=30,40 \%)$ and HCC recurrence $(n=26,34.7 \%)$. The five-year RFS and five-year OS rates in our cohort were $83.7 \%$ and $73.1 \%$, respectively.

\subsection{Comparison between CMV Antigenemia-Positive and Negative Patients}

In this study, 121 patients had positive CMV antigenemia assays, and 159 patients were CMV antigenemia-negative. Comparisons of pre-LT demographic characteristics, HCC histological features, and clinical outcomes between these two groups are summarized in Table 2. Patients with and without CMV antigenemia were similar in terms of age, sex, surgical course, and explant pathologic findings. However, the CMV antigenemia-positive patients had higher MELD scores, indicating a weakened condition before transplantation in this population. Regarding HCC histological features, there were no differences in tumor number, tumor size, vascular invasion, and Milan criteria fulfillment between the two groups. Most strikingly, the five-year recurrence-free survival rate of HCC was significantly different between groups (Figure 1): $89.2 \%$ in CMV antigenemia-positive patients, as compared with $79.9 \%$ in CMV antigenemia-negative patients $(p=0.049)$. However, there was no significant difference in the cumulative five-year OS between the two groups $(70.2 \%$ vs. $75.3 \%, p=0.255$, Figure 2 ). In addition, the antigenemia-positive group had more major surgical complications $(14.9 \%$ vs. $3.2 \%, p<0.001)$. We further analyzed the causes of death and found that the CMV antigenemia-negative patients had a larger proportion of HCC recurrence-related mortality $(16.7 \%$ vs. $51.3 \%, p=0.002)$, whereas the CMV antigenemia-positive patients faced more deaths from other bacterial or fungal infections (58.3\% vs. $23.1 \%, p=0.002$ ). These results highlight that CMV is indeed associated with lower tumor recurrence. However, severely compromised immunity increases the infection and complication rates that impede longer overall survival in the CMV-positive group.

\subsection{Univariate and Multivariate Logistic Regression for Predictors of HCC Recurrence}

Univariate and multivariate analyses were used to evaluate the potential predictors of HCC recurrence. The following clinical variables were used for univariate analysis: recipient age ( $>60$ years), recipient sex, MELD score ( $>20)$, HBV infection, HCV infection, transplant type, pre-LT AFP ( $>200 \mathrm{ng} / \mathrm{mL}$ ), pre-LT locoregional therapy, Milan criteria fulfillment, explanted liver characteristics, and CMV antigenemia. Significant results are shown in Table 3. Tumor status beyond the Milan criteria (either by radiological or histological assessment), positive CMV antigenemia assay, and histological factors such as multiple tumors, maximum tumor size $>3 \mathrm{~cm}$, satellite nodules, and vascular invasion, were subsequently considered as potential risk factors for HCC recurrence within five years in the univariate logistic regression model. These potential risk factors were entered into the multivariate analysis, showing that positive CMV antigenemia $(p=0.042$; odds ratio $(\mathrm{OR})=0.44 ; 95 \%$ confidence interval $(\mathrm{CI})=0.20-0.97)$, microscopic vascular invasion $(p=0.001 ; \mathrm{OR}=3.86 ; 95 \% \mathrm{CI}=1.78-8.36)$, and tumor status beyond the Milan criteria (explant) $(p=0.001 ; \mathrm{OR}=3.69 ; 95 \% \mathrm{CI}=1.77-7.71)$ were independent risk factors for HCC recurrence. Based on our results, the Milan criteria remains the gold standard for patient selection, and we put forward a new insight that human CMV is associated with lower HCC recurrence following LT. 
Table 2. Demographic characteristic according to PP65 antigenemia positive and negative.

\begin{tabular}{|c|c|c|c|}
\hline Factors & $\begin{array}{c}\text { CMV } \\
\text { Positive } \\
n=121\end{array}$ & $\begin{array}{c}\text { CMV } \\
\text { Negative } \\
n=159\end{array}$ & $p$-Value \\
\hline \multicolumn{4}{|c|}{ General characteristic } \\
\hline Recipient age, year-old $(>60)$ & $40(33.1 \%)$ & $46(28.9 \%)$ & 0.458 \\
\hline Recipient gender, male & $94(77.7 \%)$ & $127(79.9 \%)$ & 0.656 \\
\hline \multicolumn{4}{|c|}{ Pre-LT characteristic } \\
\hline MELD score $>20$ & $23(19.0 \%)$ & $11(6.9 \%)$ & 0.002 \\
\hline Hepatitis B infection & $70(57.9 \%)$ & $103(64.8 \%)$ & 0.237 \\
\hline Hepatitis C infection & $39(32.2 \%)$ & $40(25.2 \%)$ & 0.193 \\
\hline LDLT & $96(79.3 \%)$ & $137(86.2 \%)$ & 0.130 \\
\hline Right lobe in LDLT & $89 / 96(92.7 \%)$ & $\begin{array}{l}131 / 137 \\
(95.6 \%)\end{array}$ & 0.340 \\
\hline GRWR $\leq 0.8 \%$ in LDLT & $20 / 96(20.8 \%)$ & $\begin{array}{l}27 / 137 \\
(19.7 \%)\end{array}$ & 0.833 \\
\hline Local regional treatment before $\mathrm{LT}$ & $89(73.6 \%)$ & $123(77.4 \%)$ & 0.462 \\
\hline Beyond Milan criteria & $21(17.4 \%)$ & $25(15.7 \%)$ & 0.715 \\
\hline $\mathrm{AFP}>200 \mathrm{ng} / \mathrm{mL}$ & $18(14.9 \%)$ & $22(13.8 \%)$ & 0.805 \\
\hline \multicolumn{4}{|c|}{ Explant pathology characteristic } \\
\hline Recipients with multiple tumors & $77(63.6 \%)$ & $91(59.1 \%)$ & 0.443 \\
\hline Maximum tumor size $>3 \mathrm{~cm}$ & $39(32.2 \%)$ & $52(32.7 \%)$ & 0.933 \\
\hline Satellite nodules & $7(5.8 \%)$ & $17(10.7 \%)$ & 0.146 \\
\hline Macroscopic vascular invasion & $6(5.0 \%)$ & $11(6.9 \%)$ & 0.496 \\
\hline Microscopic vascular invasion & $23(19 \%)$ & $29(18.2 \%)$ & 0.870 \\
\hline Beyond Milan criteria & $37(30.6 \%)$ & $60(37.7 \%)$ & 0.212 \\
\hline \multicolumn{4}{|c|}{ Clinical outcome } \\
\hline Five-year recurrence free survival, cumulative & $89.2 \%$ & $79.9 \%$ & 0.049 \\
\hline Five-year overall survival, cumulative & $70.2 \%$ & $75.3 \%$ & 0.255 \\
\hline Major complications & $18(14.9 \%)$ & $5(3.2 \%)$ & $<0.001$ \\
\hline Causes of death in 5 years after LT & & & 0.004 \\
\hline Other bacterial or fungal Infection & $21(58.3 \%)$ & $9(23.1 \%)$ & 0.002 \\
\hline HCC related & $6(16.7 \%)$ & $20(51.3 \%)$ & 0.002 \\
\hline Rejection & $5(13.9 \%)$ & $3(7.7 \%)$ & 0.385 \\
\hline Others & $4(11.1 \%)$ & $7(17.9 \%)$ & 0.403 \\
\hline
\end{tabular}

Abbreviation: HCC, hepatocellular carcinoma; LT, liver transplantation; SD, standard deviation; MELD, model of end-stage liver disease; LDLT, living donor liver transplantation; GRWR, graft recipient weight ratio; AFP, alpha-fetoprotein; CMV, cytomegalovirus; PBL, peripheral blood leukocytes.

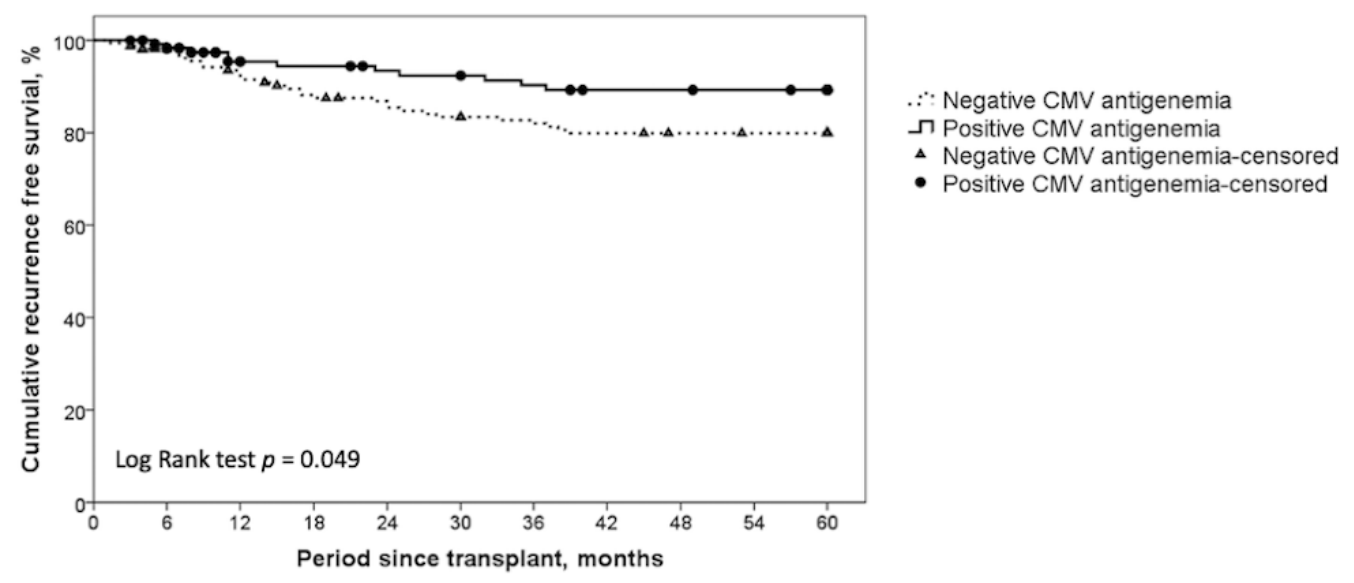

Figure 1. Kaplan-Meier method for five-year cumulative recurrence-free survival (RFS) depending on CMV antigenemia positivity and negativity. Positive CMV antigenemia group showed a significantly superior five-year RFS. 


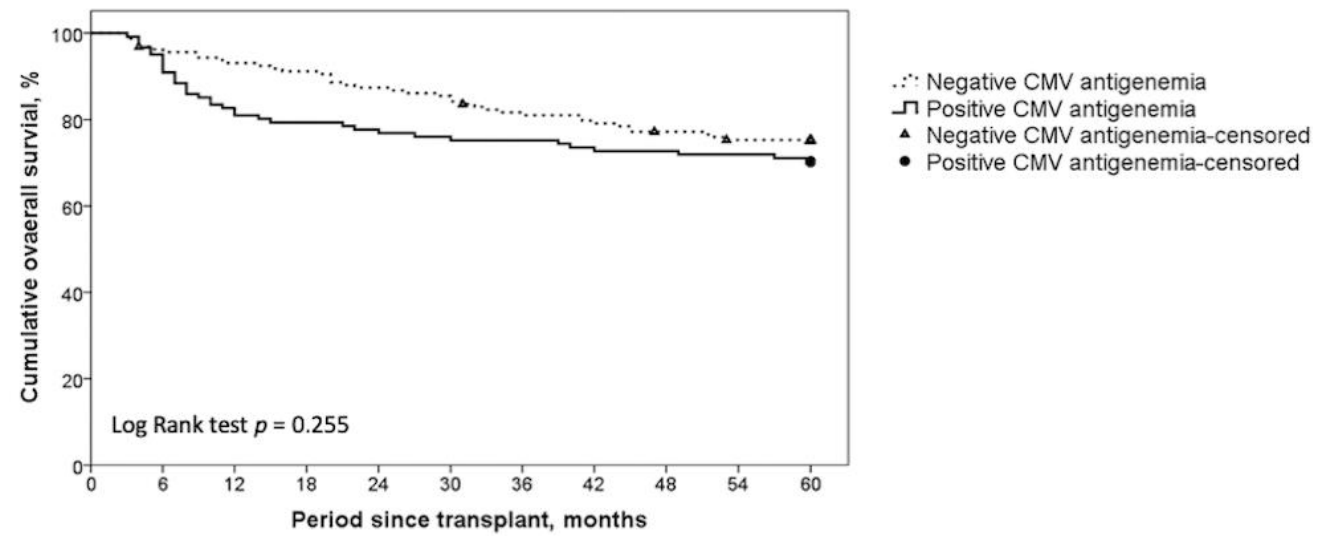

Figure 2. Kaplan-Meier method for five-year cumulative overall survival (OS) depending on positive and negative CMV antigenemia results. The five-year cumulative OS between the CMV antigenemiapositive and CMV antigenemia-negative groups were not significantly different.

Table 3. Uni-/multivariate analyses in predicting HCC recurrence after liver transplantation.

\begin{tabular}{|c|c|c|c|c|c|c|}
\hline \multirow{2}{*}{ Factors } & \multicolumn{3}{|c|}{ Univariate } & \multicolumn{3}{|c|}{ Multivariate } \\
\hline & OR & $95 \% \mathrm{CI}$ & $p$-Value & OR & $95 \% \mathrm{CI}$ & $p$-Value \\
\hline \multicolumn{7}{|c|}{ Pre-LT characteristic } \\
\hline Beyond Milan criteria (by radiology) & 3.35 & $1.59-7.07$ & 0.001 & & & \\
\hline Positive CMV antigenemia & 0.43 & $\begin{array}{l}\text { CMV stu } \\
0.21-0.90\end{array}$ & 0.025 & 0.44 & $0.20-0.97$ & 0.042 \\
\hline \multicolumn{7}{|c|}{ Explant pathology characteristic } \\
\hline Multiple tumor numbers & 2.56 & $1.17-5.60$ & 0.019 & & & \\
\hline Maximum tumor size $>3 \mathrm{~cm}$ & 2.85 & $1.45-5.60$ & 0.002 & & & \\
\hline Satellite nodule & 3.38 & $1.34-8.51$ & 0.010 & & & \\
\hline Macroscopic vascular invasion & 3.55 & $1.24-10.22$ & 0.019 & & & \\
\hline Microscopic vascular invasion & 4.72 & $2.31-9.65$ & $<0.001$ & 3.86 & $1.78-8.36$ & 0.001 \\
\hline Beyond Milan criteria (by pathology) & 4.10 & $2.05-8.21$ & $<0.001$ & 3.69 & $1.77-7.71$ & 0.001 \\
\hline
\end{tabular}

Abbreviation: OR, odds ratio; CI, confidence interval; progressive disease; LT, liver transplantation; HCC, hepatocellular carcinoma; AFP, alpha-fetoprotein; CMV, cytomegalovirus. All the factors calculated in UV were put in MV analysis with backward stepwise (Likelihood ratio).

\section{Discussion}

Liver transplantation is known to be a curative treatment option for HCC, especially for patients who are cirrhotic or not eligible for hepatectomy. Post-LT five-year OS was reported to reach $76 \%$ in recipients meeting the Milan criteria [1]. Some groups have proposed expansion beyond the Milan criteria. For example, the UCSF and up to seven criteria [21,22] have shown promising results. Therefore, the number of patients receiving transplantation to treat HCC are increasing and avoiding tumor recurrence has become an important concern. Similar to others, our study found that the Milan criteria remain a good selection tool and histological findings are the main predictors. Importantly, we found that HCC patients with CMV antigenemia were associated with significantly higher five-year RFS after transplantation than those who test negative for CMV. Although this phenomenon did not provide a benefit for overall survival, the leading cause of mortality among CMV-negative patients was HCC recurrence. Meanwhile, the major cause of death in CMV-positive patients was other bacterial or fungal infections. Our study not only emphasizes the antitumor property of CMV in LT but also reminds us of the risk of the severely immunocompromised situation in CMV-positive patients receiving LT.

With its potential oncolytic ability, the pathophysiological modulation in the host microenvironment by CMV has been widely studied as a therapeutic possibility in various cancer treatments $[23,24]$. For example, CMV infection slows tumor proliferation and promotes intrinsic caspase cancer cell apoptosis in a murine HCC study [11]. Many 
models have been designed to investigate the possible underlying mechanisms, and CMV is thought to induce tumor cell death by killing cells directly or stimulating cytokine and antitumor immune responses [9]. Studies have also reported that CMV could be used as a potential vaccine vector against cancers by eliciting a long-acting T-cell response [10,12,25], regardless of pre-existing anti-CMV cellular immunity [26]. Indeed, CMV offers some advantages that make it an attractive platform for anti-cancer studies. Regarding the immunosuppression protocol for CMV infection, we did not routinely adjust the immunosuppression for CMV antigenemia-positive patients because most of them were asymptomatic and were under preemptive treatment for CMV. We did lower the dose of steroid in patients with CMV disease. The trough levels of calcineurin inhibitor were kept at the same level ( 5 to $8 \mathrm{ng} / \mathrm{mL}$ ) in two groups. Therefore, the difference of recurrence free survival was not related to the use of calcineurin inhibitor, which is known to be associated with de novo malignancy or recurrence of malignancy after solid organ transplantation. It is also worthy to mention that everolimus, an inhibitor of mammalian target of rapamycin, was reported to alleviate CMV infection [27]. Everolimus has anti-cancer and immunosuppressive effects and can be used for the prevention or treatment of HCC recurrence following LT $[28,29]$. The antiviral efficacy of everolimus may counteract the oncolytic effect of CMV in transplantation.

We do not advocate ignoring the negative impact of CMV on LT. CMV infection has been considered a major concern for post-transplant recipients. CMV disease is common in $8-29 \%$ of all LT recipients [30-32]. Progression of CMV disease often results in major organ failure and death $[33,34]$. This common opportunistic pathogen incurs a more complex infectious condition in immunocompromised recipients following organ transplantation $[35,36]$. We encourage aggressive CMV treatment once it is detected due to its lethality and many potential risks in transplant recipients [8]. However, if the clinical presentation of CMV infection becomes latent, we may have some room to make our treatment policy more flexible.

Our study has some limitations. First, compared to the CMV qPCR method, CMV pp65 antigenemia is not an ideal quantitative method for detecting CMV infection [37-39]. Second, we performed the CMV pp65 antigenemia assay weekly during hospitalization, and a longer period of CMV surveillance may be needed. Third, this study was conducted at a single center and was consequently subjected to its bias of CMV treatment and monitoring protocol. Accordingly, further prospective, and multi-center research with the CMV qPCR method may be required to verify our results.

\section{Conclusions}

In conclusion, CMV reduces the risk of HCC recurrence following LT. This tumor suppressive property does not lead to prolonged overall survival, especially in severely immunocompromised patients who are vulnerable to other infections. Nevertheless, the potential anti-HCC benefit we observed in survivors of CMV infection after LT deserves further investigation. Our study provides a new viewpoint, offering a magnificent possibility for oncolytic viruses in transplantation.

Author Contributions: P.-J.H. participated in the writing of the paper, research design, performance of the research, and data analysis. H.-C.H., J.-C.L., Y.-C.W., C.-H.C., T.-H.W., T.-J.W., H.-S.C. and K.-M.C. participated in research design, and performance of the research. W.-C.L. and C.-F.L. participated in research design and data analysis. All authors have read and agreed to the published version of the manuscript.

Funding: This research received no external funding.

Institutional Review Board Statement: The study was conducted according to the guidelines of the Declaration of Helsinki and approved by the Institutional Review Board of Chang-Gung Memorial Hospital (IRB No. 202101491B0). 
Informed Consent Statement: Patients were not required to give informed consent to the study because the analysis used anonymous clinical data that were obtained after each patient agreed to treatment by written consent.

Data Availability Statement: The data presented in this study are available on request from the corresponding author.

Acknowledgments: The authors gratefully acknowledge all LT team members who dedicate their best efforts in taking care of transplant patients in our hospital.

Conflicts of Interest: The authors declare no conflict of interest.

\section{References}

1. Mazzaferro, V.M.; Regalia, E.; Doci, R.; Andreola, S.; Pulvirenti, A.; Bozzetti, F.; Montalto, F.; Ammatuna, M.; Morabito, A.; Gennari, L. Liver Transplantation for the Treatment of Small Hepatocellular Carcinomas in Patients with Cirrhosis. N. Engl. J. Med. 1996, 334, 693-700. [CrossRef]

2. Roayaie, S.; Schwartz, J.D.; Sung, M.W.; Emre, S.H.; Miller, C.M.; Gondolesi, G.E.; Krieger, N.R.; Schwartz, M.E. Recurrence of hepatocellular carcinoma after liver transplant: Patterns and prognosis. Liver Transplant. 2004, 10, 534-540. [CrossRef] [PubMed]

3. Filgueira, N.A. Hepatocellular carcinoma recurrence after liver transplantation: Risk factors, screening and clinical presentation. World J. Hepatol. 2019, 11, 261-272. [CrossRef] [PubMed]

4. Valdivieso, A.; Bustamante, J.; Gastaca, M.; Uriarte, J.G.; Ventoso, A.; Ruiz, P.; Ernandez, J.R.; Pijoan, I.; Testillano, M.; Suarez, M.J.; et al. Management of Hepatocellular Carcinoma Recurrence After Liver Transplantation. Transplant. Proc. 2010, 42, 660-662. [CrossRef]

5. Zimmerman, M.A.; Ghobrial, R.M.; Tong, M.J.; Hiatt, J.R.; Cameron, A.M.; Hong, J.; Busuttil, R.W. Recurrence of Hepatocellular Carcinoma Fol-lowing Liver Transplantation: A Review of Preoperative and Postoperative Prognostic Indicators. Arch. Surg. 2008, 143, 182-188. [CrossRef]

6. Linares, L.; Sanclemente, G.; Cervera, C.; Hoyo, I.; Cofán, F.; Ricart, M.; Pérez-Villa, F.; Navasa, M.; Marcos, M.; Antón, A.; et al. Influence of Cytomegalovirus Disease in Outcome of Solid Organ Transplant Patients. Transplant. Proc. 2011, 43, 2145-2148. [CrossRef]

7. Kim, J.M.; Kim, S.J.; Joh, J.W.; Kwon, C.H.D.; Song, S.; Shin, M.; Lee, S.K.; Moon, J.I.; Kim, G.S.; Hong, S.H. Is cytomegalovirus infection dangerous in cytomegalovi-rus-seropositive recipients after liver transplantation? Liver Transpl. 2011, 17, 446-455. [CrossRef]

8. Hung, H.; Hsu, P.; Lee, J.; Wang, Y.; Cheng, C.H.; Wu, T.-J.; Wu, T.-H.; Chou, H.; Chan, K.; Lee, W.; et al. Plasma cytomegalovirus DNA load predicts outcomes in liver transplant recipients. Immunity Inflamm. Dis. 2020, 9, 134-143. [CrossRef] [PubMed]

9. Herbein, G.; Nehme, Z. Tumor Control by Cytomegalovirus: A Door Open for Oncolytic Virotherapy? Mol. Ther--Oncolytics 2020, 17, 1-8. [CrossRef]

10. Klyushnenkova, E.N.; Kouiavskaia, D.V.; Parkins, C.J.; Caposio, P.; Botto, S.; Alexander, R.B.; Jarvis, M.A. A Cytomegalovirusbased Vaccine Expressing a Single Tumor-specific CD8+ T-cell Epitope Delays Tumor Growth in a Murine Model of Prostate. Cancer J. Immunother. 2012, 35, 390-399. [CrossRef] [PubMed]

11. Kumar, A.; Coquard, L.; Pasquereau, S.; Russo, L.; Valmary-Degano, S.; Borg, C.; Pothier, P.; Herbein, G. Tumor control by human cytomegalovirus in a murine model of hepatocellular carcinoma. Mol. Ther--Oncolytics 2016, 3, 16012. [CrossRef] [PubMed]

12. Qiu, Z.; Huang, H.; Grenier, J.M.; Perez, O.A.; Smilowitz, H.M.; Adler, B.; Khanna, K.M. Cytomegalovirus-Based Vaccine Expressing a Modified Tumor Antigen Induces Potent Tumor-Specific CD8+ T-cell Response and Protects Mice from Melanoma. Cancer Immunol. Res. 2015, 3, 536-546. [CrossRef] [PubMed]

13. Wu, T.J.; Dahiya, D.; Lee, C.S.; Lee, C.F.; Chou, H.S.; Chan, K.M.; Lee, W.C. Impact of portal venous hemodynamics on indices of liver function and graft regeneration after right lobe living donor liver transplantation. Liver Transpl. 2011, 17, 1035-1045. [CrossRef] [PubMed]

14. Chan, K.M.; Cheng, C.H.; Wu, T.H.; Wu, T.J.; Chou, H.S.; Lee, C.S.; Lee, W.C. Clinical strategy for the reconstruction of middle hepatic vein tributaries in right liver living donor liver transplantation. World J. Surg. 2014, 38, 2927-2933. [CrossRef]

15. Lee, W.; Lee, C.; Wu, T.J.; Soong, R.; Cheng, C.; Chou, H.S.; Chan, K. Adult Living Donor Liver Transplantation Across ABO-Incompatibility. Medicine 2015, 94, e1796. [CrossRef]

16. Yao, F.Y.; Ferrell, L.; Bass, N.M.; Watson, J.J.; Bacchetti, P.; Venook, A.; Roberts, J.P.; Ascher, N.L. Liver transplantation for hepatocellular carcinoma: Expansion of the tumor size limits does not adversely impact survival. Hepatology 2001, 33, 1394-1403. [CrossRef]

17. Ljungman, P.; Griffiths, P.; Paya, C. Definitions of Cytomegalovirus Infection and Disease in Transplant Recipients. Clin. Infect. Dis. 2002, 34, 1094-1097. [CrossRef]

18. McBride, J.M.; Sheinson, D.; Jiang, J.; Lewin-Koh, N.; Werner, B.G.; Chow, J.K.L.; Wu, X.; Tavel, J.A.; Snydman, D.R. Correlation of Cytomegalovirus (CMV) Disease Severity and Mortality With CMV Viral Burden in CMV-Seropositive Donor and CMVSeronegative Solid Organ Transplant Recipients. Open Forum Infect. Dis. 2019, 6, ofz003. [CrossRef]

19. Dahiya, D.; Lee, C.F.; Chan, K.M.; Wu, T.J.; Chou, H.S.; Cheng, S.S.; Lee, W.C. A short-term preemptive treatment for cytomegalovirus in-fection in seropositive patients after liver transplantation. J. Hepatobiliary Pancreat. Sci. 2011, 18, 32-38. [CrossRef] 
20. Clavien, P.A.; Barkun, J.; De Oliveira, M.L.; Vauthey, J.N.; Dindo, D.; Schulick, R.D.; Makuuchi, M.; de Santibañes, E.; Pekolj, J.; Slankamenac, K.; et al. The Clavien-Dindo classification of surgical complications: Five-year experience. Ann. Surg. 2009, 250, 187-196. [CrossRef]

21. Yao, F.Y.; Xiao, L.; Bass, N.M.; Kerlan, R.; Ascher, N.L.; Roberts, J.P. Liver Transplantation for Hepatocellular Carcinoma: Validation of the UCSF-Expanded Criteria Based on Preoperative Imaging. Arab. Archaeol. Epigr. 2007, 7, 2587-2596. [CrossRef]

22. Mazzaferro, V.; Llovet, J.M.; Miceli, R.; Bhoori, S.; Schiavo, M.; Mariani, L.; Camerini, T.; Roayaie, S.; Schwartz, E.M.; Grazi, G.L.; et al. Predicting survival after liver transplantation in patients with hepatocellular carcinoma beyond the Milan criteria: A retrospective, exploratory analysis. Lancet Oncol. 2009, 10, 35-43. [CrossRef]

23. Fukuhara, H.; Ino, Y.; Todo, T. Oncolytic virus therapy: A new era of cancer treatment at dawn. Cancer Sci. 2016, 107, 1373-1379. [CrossRef]

24. Erkes, D.A.; Wilski, N.A.; Snyder, C.M. Intratumoral infection by CMV may change the tumor environment by directly interacting with tumor-associated macrophages to promote cancer immunity. Hum. Vaccines Immunother. 2017, 13, 1778-1785. [CrossRef] [PubMed]

25. Nejad, E.B.; Ratts, R.B.; Panagioti, E.; Meyer, C.; Oduro, J.D.; Cicin-Sain, L.; Arens, R.; Früh, K.; van der Burg, S.H. Demarcated thresholds of tumor-specific CD8 T cells elicited by MCMV-based vaccine vectors provide robust correlates of protection. J. Immunother. Cancer 2019, 7, 25. [CrossRef]

26. Klenerman, P. The (gradual) rise of memory inflation. Immunol. Rev. 2018, 283, 99-112. [CrossRef] [PubMed]

27. Tan, L.; Sato, N.; Shiraki, A.; Yanagita, M.; Yoshida, Y.; Takemura, Y.; Shiraki, K. Everolimus delayed and suppressed cytomegalovirus DNA synthesis, spread of the infection, and alleviated cytomegalovirus infection. Antivir. Res. 2018, 162, 30-38. [CrossRef]

28. Kang, I.; Lee, J.G.; Choi, S.H.; Kim, H.J.; Han, D.H.; Choi, G.H.; Kim, M.S.; Choi, J.S.; Kim, S.I.; Joo, D.J. Impact of everolimus on survival after liver transplantation for hepatocellular carcinoma. Clin. Mol. Hepatol. 2021, 27, 589-602. [CrossRef] [PubMed]

29. Lee, S.-G.; Jeng, L.-B.; Saliba, F.; Soin, A.S.; Lee, W.-C.; De Simone, P.; Nevens, F.; Suh, K.-S.; Fischer, L.; Joo, D.J.; et al. Efficacy and Safety of Everolimus With Reduced Tacrolimus in Liver Transplant Recipients: 24-month Results From the Pooled Analysis of 2 Randomized Controlled Trials. Transplantation 2020, 105, 1564-1575. [CrossRef]

30. Gane, E.; Saliba, F.; Valdecasas, G.J.; O'Grady, J.; Pescovitz, M.D.; Lyman, S.; Robinson, A.C. Randomised trial of efficacy and safety of oral ganciclovir in the prevention of cytomegalovirus disease in liver-transplant recipients. The Oral Ganciclovir International Transplantation Study Group [corrected]. Lancet 1997, 350, 1729-1733. [CrossRef]

31. Singh, N.; Wagener, M.M. Strategies To Prevent Organ Disease by Cytomegalovirus in Solid Organ Transplant Recipients. Ann. Intern. Med. 2006, 144, 456-457. [CrossRef] [PubMed]

32. Paya, C.; Humar, A.; Dominguez, E.; Washburn, K.; Blumberg, E.; Alexander, B.; Freeman, R.; Heaton, N.; Pescovitz, M.D.; Valganciclovir Solid Organ Transplant Study Group. Efficacy and Safety of Valganciclovir vs. Oral Ganciclovir for Prevention of Cytomegalovirus Disease in Solid Organ Transplant Recipients. Am. J. Transplant. 2004, 4, 611-620. [CrossRef] [PubMed]

33. Rafailidis, P.I.; Mourtzoukou, E.G.; Varbobitis, I.C.; Falagas, E.M. Severe cytomegalovirus infection in apparently immunocompetent patients: A systematic review. Virol. J. 2008, 5, 47. [CrossRef] [PubMed]

34. Razonable, R.R.; Emery, V. Management of CMV infection and disease in transplant patients. 27-29 February 2004. Herpes 2004, 11, 77-86. [PubMed]

35. Peleg, A.Y.; Husain, S.; Qureshi, Z.A.; Silveira, F.P.; Sarumi, M.; Shutt, K.; Kwak, E.J.; Paterson, D. Risk Factors, Clinical Characteristics, and Outcome of Nocardia Infection in Organ Transplant Recipients: A Matched Case-Control Study. Clin. Infect. Dis. 2007, 44, 1307-1314. [CrossRef]

36. Humar, A.; Kumar, D.; Raboud, J.; Caliendo, A.M.; Moussa, G.; Levy, G.; Mazzulli, T. Interactions between cytomegalovirus, human her-pesvirus-6, and the recurrence of hepatitis C after liver transplantation. Am. J. Transplant. 2002, 2, 461-466. [CrossRef]

37. Razonable, R.R.; Paya, C.V.; Smith, T.F. Role of the laboratory in diagnosis and management of cytomegalovirus infection in hem-atopoietic stem cell and solid-organ transplant recipients. J. Clin. Microbiol. 2002, 40, 746-752. [CrossRef]

38. Li, H.; Dummer, J.S.; Estes, W.R.; Meng, S.; Wright, P.F.; Tang, Y.-W. Measurement of Human Cytomegalovirus Loads by Quantitative Real-Time PCR for Monitoring Clinical Intervention in Transplant Recipients. J. Clin. Microbiol. 2003, 41, 187-191. [CrossRef]

39. Piiparinen, H.; Höckerstedt, K.; Grönhagen-Riska, C.; Lautenschlager, I. Comparison of two quantitative CMV PCR tests, Cobas Amplicor CMV Monitor and TaqMan assay, and pp65-antigenemia assay in the determination of viral loads from peripheral blood of organ transplant patients. J. Clin. Virol. 2004, 30, 258-266. [CrossRef] [PubMed] 